\title{
A 31P nuclear magnetic resonance study of phosphate levels in roots of ectomycorrhizal and nonmycorrhizal plants of Castanea sativa Mill.
}

Received: 28 July 1998 / Accepted: 21 October 1998

\begin{abstract}
P-Nuclear Magnetic Resonance (NMR) was used to assess phosphate distribution in ectomycorrhizal and nonmycorrhizal roots of Castanea sativa Mill. as well as in the mycorrhizal fungus Pisolithus tinctorius in order to gain insight into phosphate trafficking in these systems. The fungus $P$. tinctorius accumulated high levels of polyphosphates during the rapid phase of growth. Mycorrhizal and nonmycorrhizal roots accumulate orthophosphate. Only mycorrhizal roots presented polyphosphates. The content in polyphosphates increased along the 3 months of mycorrhiza formation. In mycorrhizal roots of plants cultured under axenic conditions, the orthophosphate pool decreased along the culture time. In nonmycorrhizal roots the decrease in the orthophosphate content was less pronounced. The level of orthophosphate in mycorrhizal roots was significantly lower than in nonmycorrhizal ones, which indicates that this system relies upon the fungal polyphosphates as a major source of phosphate.
\end{abstract}

Key words Castanea sativa - Pisolithus tinctorius . Ectomycorrhiza $\cdot$ Phosphate $\cdot$ NMR

\section{Introduction}

Ectomycorrhiza offer several advantages to plants, namely increased root absorbing area (Bowen 1973; Harley and Smith 1983) and enhanced nutrient uptake (Harley and Smith 1983). Ectomycorrhiza can also increase nu-

A. Martins (®)

Escola Superior Agrária de Bragança, Bragança, Portugal e-mail: amartins@ipb.pt

M. Santos · H. Santos

Instituto de Tecnologia Química e Biológica,

Universidade Nova de Lisboa, Apt. 127, P-2780 Oeiras,

Portugal

M.S. Pais

Departamento de Biologia Vegetal,

Faculdade de Ciências de Lisboa, Bloco C2,

P-1700 Lisboa, Portugal trient content of plants growing in low nutrient soils, thereby promoting growth (Jones et al. 1991). The improved nutrient status of mycorrhizal plants, especially in $\mathrm{P}$ and $\mathrm{N}$ nutrition, has been reported by several authors (Bougher et al. 1990; Jones et al. 1990, 1991; Finlay 1992; Botton 1996; Finlay et al. 1996). Increase in net photosynthesis, following increase in $\mathrm{N}$ and $\mathrm{P}$, was reported for different species (Osman et al. 1977; Longstreth and Nobel 1980; Swada et al. 1982; Reid et al. 1983). Increased $P$ and photosynthetic rates followed by decreased $\mathrm{N}$ content of pine seedlings leaves were also reported by Conjeaud et al. (1996). The increase in phosphate concentration in mycorrhizal plants was also correlated with increased photosynthetic rates, as the phosphate level of the chloroplast influences photosynthetic rates (Osmond 1981; Coombs 1985; Foyer and Spencer 1986; Jakobsen 1991). However, increase of phosphate content in nonmycorrhizal plants did not result in increased photosynthesis (Conjeaud et al. 1996). According to these authors the stimulation of the net photosynthetic rates by mycorrhizal infection is not related to nutrition, although the results obtained can be consistent with the photosynthate source-sink concept.

Son and Smith (1988) studied the interactions between photon irradiance and phosphorus nutrition in mycorrhizal and control plants. They suggest that at high irradiance there is a positive mycorrhizal growth response in plants grown without additional P. In contrast, a reduced or negative mycorrhizal growth response occurs under low irradiance conditions, although the extent of the infection was similar (Son and Smith 1988). Micropropagated chestnut plants showed increased growth and photosynthetic rates following in vitro mycorrhization with P. tinctorius (Martins et al. 1996, 1997).

Polyphosphates occur in a wide range of fungi as well as in the fungal component of all types of mycorrhizal associations examined so far (Chilvers et al. 1985; MacFall et al. 1992; Ashford et al. 1994). It has been suggested that it plays a role in plant nutrition by allowing rapid accumulation of phosphate in an inactive form when phosphate is abundant (Harley and Smith 1983; 
Ashford et al. 1994). In mycorrhiza, the uptake of $P$ seems to be first as a Pi pool, followed by accumulation as polyphosphates (Grellier et al. 1989; MacFall et al. 1992). When phosphate level is low, it is slowly transferred to the partner (Harley and Smith 1983; MacFall et al. 1992; Ashford et al. 1994). This is a selective advantage in conditions where phosphate availability fluctuates.

Currently there is a great interest in understanding the role of the extramatrical mycelium in phosphate uptake and transfer to the symbiont interface (Ashford et al. 1994). It was suggested that phosphate is translocated along hyphae as polyphosphate granules inside vacuoles (Cox et al. 1980). However, this contention has been challenged, and these granules are most likely artifacts (Ashford et al. 1994, Smith and Read 1997). Ectomycorrhizal hyphae actively growing in axenic culture are thought to accumulate phosphate mainly as orthophosphate, in contrast to the fungal mantle and ectomycorrhizal fungi during stationary phase, which store it as polyphosphates (Martin et al. 1985; Ashford et al. 1994). Metachromatic vacuolar material can easily be observed in several strains of $P$. tinctorius when actively growing in liquid medium or on agar (Ashford et al. 1994). According to the same authors, the vacuolar phosphate, identified as polyphosphate, occurs in vivo in soluble form counterbalanced by potassium ions. The occurrence of polyphosphates has been demonstrated in beech mycorrhiza by in vivo ${ }^{31} \mathrm{P}-\mathrm{NMR}$ (Loughman and Ratcliff 1984) as well as in ectomycorrhizal fungi in pure cultures (Martin et al. 1985).

Here we report on the use of in vivo ${ }^{31} \mathrm{P}-\mathrm{NMR}$ to determine phosphate distribution in ectomycorrhizal and nonmycorrhizal plants of $C$. sativa in order to gain insight into phosphate trafficking in these systems.

\section{Materials and methods}

Castanea sativa micropropagated plants were obtained as previously described (Martins et al. 1996). The fungus Pisolithus tinctorius (Pers.) Coker and Couch isolate 289/Marx kindly supplied by Dr. Ingrid Kottke (Tübingen University) was maintained on a MMN solid medium (Marx 1969).

\section{Fungus production}

Production of fungal inoculum for plant inoculation was made in solid modified MMN medium (absence of malt extract, casaminoacids) and with $0.9 \mathrm{mM}\left(\mathrm{NH}_{4}\right)_{2} \mathrm{HPO}_{4}, 1.8 \mathrm{mM} \mathrm{KH} \mathrm{PO}_{4}$. The mycelia used for NMR analysis were produced in static liquid cultures in $600 \mathrm{ml}$ culture flasks with $100 \mathrm{ml}$ half strength MS liquid medium with $1.25 \mathrm{mM} \mathrm{KH}_{2} \mathrm{PO}_{4}$ and $10 \mathrm{~g} / \mathrm{l}$ sucrose, to facilitate fungus collection.

\section{Mycorrhizal synthesis}

Plant inoculation was performed in petri dishes plated in slant with half strength MS solid medium with $0.625 \mathrm{mM} \mathrm{KH_{2 }} \mathrm{PO}_{4}$ and $10 \mathrm{~g} / \mathrm{l}$ sucrose. Fungus was inoculated 3 weeks before plant transfer. In vitro mycorrhization of micropropagated plants was induced $4-5$ weeks after plant rooting, by transfer of rooted plants to the petri dishes inoculated 3 weeks before with mycelium. A portion of the petri dishes with roots was covered with aluminum foil to prevent oxidation of root phenols by light. Control plants were transferred to petri dishes without fungus and maintained under the same conditions. Plants were maintained in a growth chamber under a $16 \mathrm{~h}$ light period, $\sim 100 \mathrm{mE} \mathrm{m}^{-2} \mathrm{~s}^{-1}$ quantum flux density, $25^{\circ} \mathrm{C}$ during light period and $19^{\circ} \mathrm{C}$ during dark period for 3 weeks to 5 months for NMR trials.

\section{Sample preparation for NMR}

Samples of excised root systems of mycorrhizal or control plants as well as samples of pure cultures of the fungus were prepared for NMR analysis. The root systems of mycorrhizal and control plants were excised on melting ice, cut in pieces about $1 \mathrm{~cm}$ long, weighed and transferred to a $10 \mathrm{~mm}$ NMR tube $30 \mathrm{~min}$ after excision. Similar masses of material and similar packing were used in the different experiments. A $1 \%$ sucrose solution saturated in $\mathrm{O}_{2}$ and containing $5 \%{ }^{2} \mathrm{H}_{2} \mathrm{O}$ was continuously circulated at a rate of $10 \mathrm{ml} \mathrm{min}^{-1}$, by using two peristaltic pumps and a perfusion device with gas-impermeable Tygon connecting tubes. Two glass capillaries were fitted into the NMR tube, one positioned a few millimeters from the bottom (inlet of medium) and the other just above the cotton wool filter that was used to restrict the volume of the biological material (outlet of medium). For the fungus grown in pure culture, a $1 \%$ sucrose solution containing $5 \%{ }^{2} \mathrm{H}_{2} \mathrm{O}$ was used for the perfusion medium.

\section{NMR Spectroscopy}

${ }^{31} \mathrm{P}-\mathrm{NMR}$ spectra were recorded on a Bruker AMX-500 spectrometer using a quadruple nuclei probe head $(10 \mathrm{~mm})$ with the following conditions: $45^{\circ}$ flip angle, $0.7 \mathrm{~s}$ recycle delay, $8 \mathrm{~K}$ acquisition data points and $20 \mathrm{kHz}$ spectral width. The acquisition time of each spectrum was approximately $40 \mathrm{~min}$. Signal to noise was enhanced using a $16 \mathrm{~Hz}$ or $25 \mathrm{~Hz}$ exponential multiplication for the spectra of plants and fungus, respectively. No $1 \mathrm{H}$ decoupling was applied. Chemical shifts were referenced to external $85 \% \mathrm{H}_{3} \mathrm{PO}_{4}$. In all the experiments, the probe head temperature was kept at $25^{\circ} \mathrm{C}$. Vacuolar $\mathrm{pH}$ was determined from the chemical shift of the orthophosphate resonance and using a calibration curve obtained with a solution containing $50 \mathrm{mM}$ Mops, $1 \mathrm{mM}$ magnesium chloride and $20 \mathrm{mM}$ potassium phosphate.

Phosphate quantification

Extraction of total $\mathrm{P}$ from roots leaves and stems of mycorrhizal and nonmycorrhizal plants was performed according to Bowman (1988). Phosphate quantification was made 30, 40, 60 and 90 days after mycorrhizal induction in vitro by the molybdenum blue method according to John (1970).

Nitrogen quantification

Total nitrogen extraction and quantification were made according to Keeney and Nelson (1982; in Forster 1995) 30, 40, 60 and 90 days after mycorrhizal induction in vitro.

\section{Results and discussion}

${ }^{31} \mathrm{P}-\mathrm{NMR}$ spectra of the fungus samples, either in pure culture or extramatrical hyphae collected from petri dishes containing 1-month-old mycorrhizas, showed the presence of resonances due to the vacuolar orthophosphate pool and the polyphosphates pool (Fig. 1) as al- 


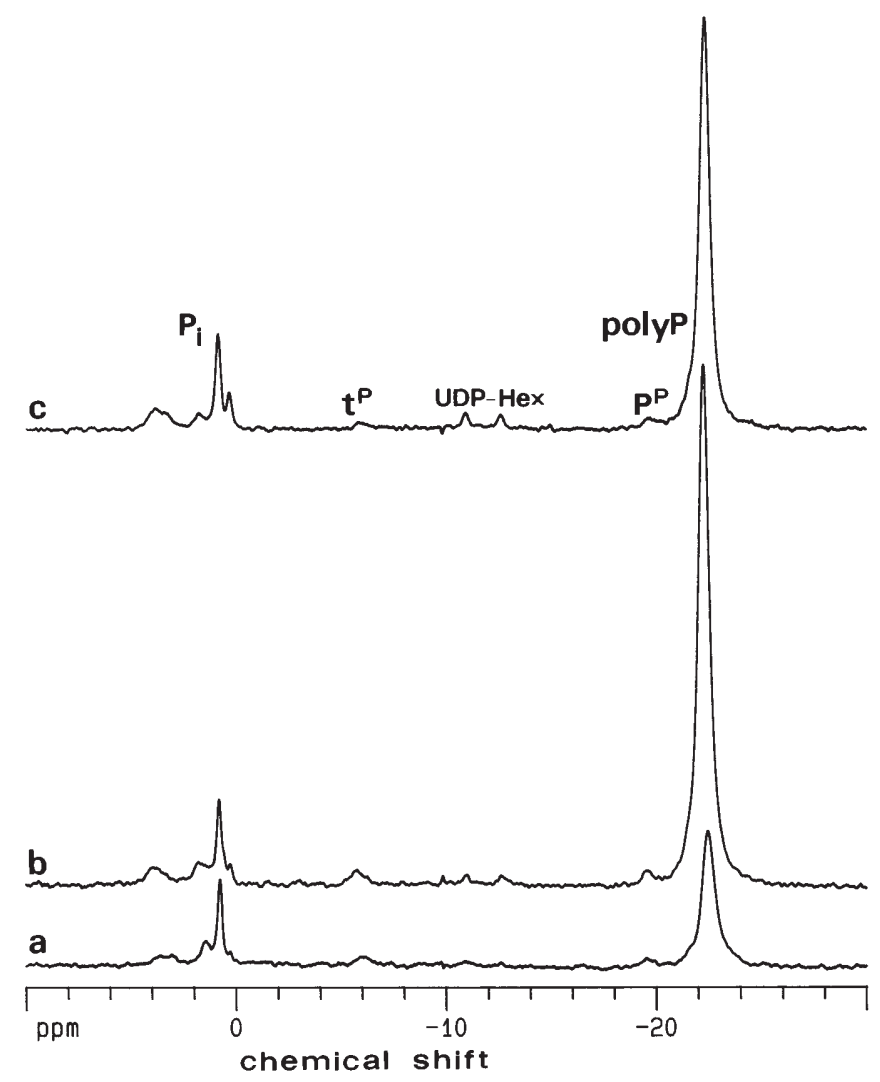

Fig. $1{ }^{31} \mathrm{P}-\mathrm{NMR}$ spectra of the fungus Pisolithus tinctorius grown in axenic conditions with different ages: (a) 7 days, (b) 15 days and (c) 1.5 months. $P i$, intracellular orthophosphate; $t P$, terminal phosphate; UDP-Hexose, uridine diphosphate hexose; $P P$, penultimate phosphate; poly $P$, polyphosphates

ready reported for P. tinctorius (Ashford et al. 1994) and for other fungi (Martin et al. 1983, 1985; Chilvers et al. 1985). The spectrum of a 15-day-old mycelium was dominated by the strong polyphosphates resonance at -22.3 , but a resonance due to intracellular inorganic phosphate was also clearly observed at $0.79 \mathrm{ppm}$. Resonances due to the terminal and penultimate groups of polyphosphates as well as UDP-hexoses were also detected. The intensity of the resonance due to polyphosphates increased considerably from day 7 to day 15 of culture and then decreased in 46-day-old mycelium. It is well known that the NMR visibility of polyphosphates changes considerably with the degree of mobility of the polymer. Therefore, this decrease in the intensity of the polyphosphates resonance may reflect a higher degree of immobilization of the polymer in the late growth phase.

The NMR spectra obtained for $P$. tinctorius confirm the presence of both orthophosphate and polyphosphates as reported for other fungi, especially when rapidly growing in axenic culture (Grellier et al. 1989; Cairney and Smith 1992; Ashford et al. 1994). According to Ashford et al. (1994), phosphates are transported in fungi as soluble polyphosphates. Changes in polyphosphate distribution will have a low effect on the osmotic poten-
A
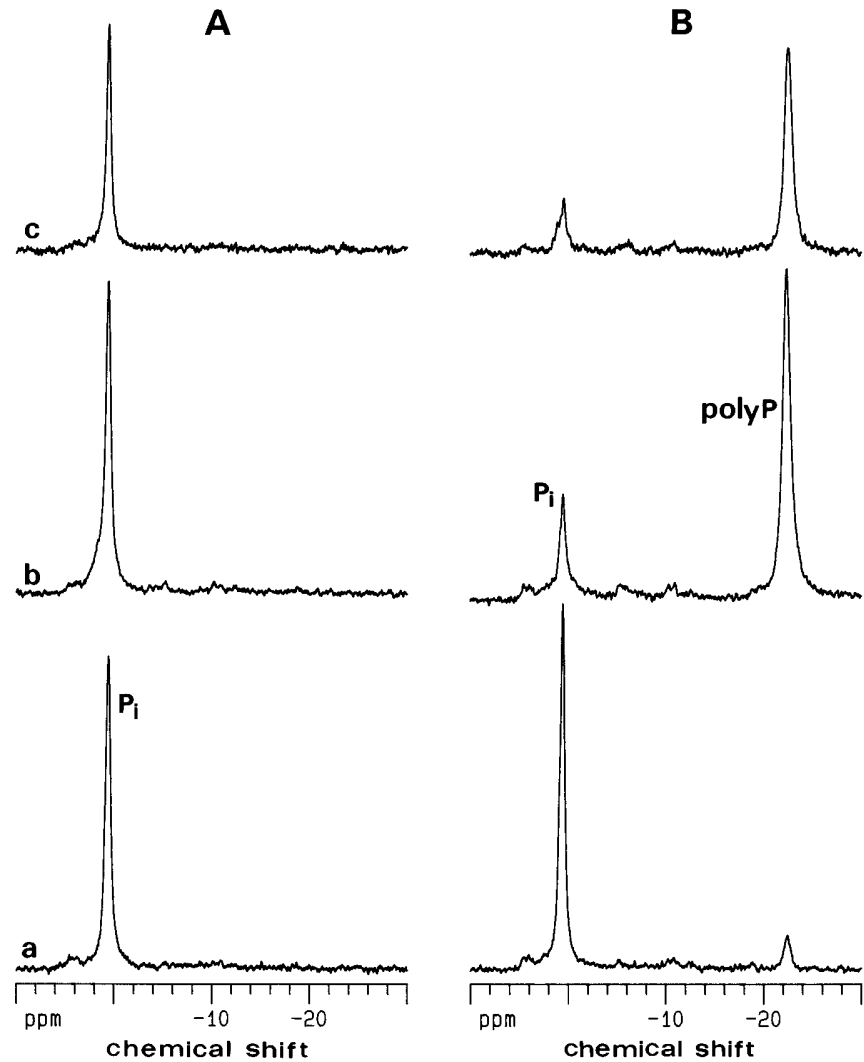

Fig. $2{ }^{31}$ P-NMR spectra of control (A) and mycorrhizal (B) chestnut roots at different mycorrhization times: (a) 3 weeks after mycorrhizal induction; (b) 1 month after mycorrhizal induction; (c) 3 months after mycorrhizal induction. $P i$, intracellular orthophosphate; polyP, polyphosphates

tial of the cell. Polyphosphates are high-energy compounds, which can directly phosphorylate compounds such as ADP, and so polyphosphate transfer along hyphae involves the transfer of energy as well as of phosphate.

Maintenance of a relatively constant internal Pi concentration has been described for fungi growing in pure culture, polyphosphates acting as a sink for removal of Pi (MacFall et al. 1992). When there is excess of intracellular $\mathrm{Pi}$, the synthesis of polyphosphates acts as a mechanism for removal and storage of Pi. When present in a P-limiting medium, the stored polyphosphates are hydrolyzed, releasing $\mathrm{Pi}$ and maintaining $\mathrm{Pi}$ concentration within the fungal cell (Martin et al. 1985; MacFall et al. 1992).

The spectra obtained for mycorrhizal chestnut roots at different mycorrhization times as well as those obtained for control plants (no induction of mycorrhization) are compared in Fig. 2. The intracellular $\mathrm{pH}$ of the vacuolar compartment was 5.2 for the mycorrhizal and for the control plants which is the characteristic $\mathrm{pH}$ of the vacuole. The most striking difference between the two sets of spectra is the presence of polyphosphates in the mycorrhizal roots resulting from the presence of the fungus in 
Table 1 Phosphate content $(\mu \mathrm{mol} / \mathrm{g} \mathrm{dw})$ of roots, leaves stems and total plant of nonmycorrhizal (CR, CL, CS, CT) and mycorrhizal (MR, ML, MS, MT) plants after 30, 40, 60 and 90 days of mycorrhizal synthesis. Mean values within a sampling followed by different letters are significantly different at $\mathrm{P}<0.05$

\begin{tabular}{lllll}
\hline$\mu \mathrm{mol} / \mathrm{g} \mathrm{dw}$ & 30 days & 40 days & 60 days & 90 days \\
\hline $\mathrm{CR}$ & $154.0 \mathrm{a}$ & $114.0 \mathrm{a}$ & $75.0 \mathrm{a}$ & $53.0 \mathrm{a}$ \\
MR & $224.0 \mathrm{~b}$ & $172.0 \mathrm{~b}$ & $79.0 \mathrm{~b}$ & $63.0 \mathrm{~b}$ \\
$\mathrm{CS}$ & $133.0 \mathrm{a}$ & $109.0 \mathrm{a}$ & $61.0 \mathrm{a}$ & $56.0 \mathrm{a}$ \\
MS & $143.0 \mathrm{~b}$ & $123.0 \mathrm{~b}$ & $72.0 \mathrm{~b}$ & $60.0 \mathrm{~b}$ \\
$\mathrm{CL}$ & $95.0 \mathrm{a}$ & $110.0 \mathrm{a}$ & $51.0 \mathrm{a}$ & $45.0 \mathrm{a}$ \\
ML & $108.0 \mathrm{~b}$ & $126.0 \mathrm{~b}$ & $60.0 \mathrm{~b}$ & $49.0 \mathrm{~b}$ \\
$\mathrm{CT}$ & $127.0 \mathrm{a}$ & $111.0 \mathrm{a}$ & $63.0 \mathrm{a}$ & $54.0 \mathrm{a}$ \\
MT & $156.0 \mathrm{~b}$ & $142.0 \mathrm{~b}$ & $70.0 \mathrm{~b}$ & $61.0 \mathrm{~b}$ \\
\hline
\end{tabular}

the root detectable after 3 weeks of mycorrhizal synthesis.

The roots of control plants, cultivated under the same axenic conditions, showed a progressive decrease of orthophosphate content with age. A sharper decrease is observed in mycorrhizal roots. Comparing the root NMR spectra of mycorrhizal and control plants for identical culture times it is observed that orthophosphate is significantly lower in mycorrhizal roots (containing polyphosphates), with the exception of the shortest time of mycorrhization tested (3 weeks). In that case, the levels of orthophosphate in mycorrhizal and control roots are similar. This result is not surprising since the degree of mycorrhization at this stage, as judged from the intensity of the polyphosphates resonance, is low (Fig. 2B); consequently, the metabolism of the plant may have not yet been significantly affected.

Chestnut mycorrhizas are able to accumulate phosphate, mostly in the form of polyphosphates, in contrast to nonmycorrhizal roots, which accumulate only orthophosphate (Fig. 2). This demonstrates the ability of mycorrhizal fungi to accumulate phosphate in an osmotically inactive form when phosphate is abundant and the capacity to transfer this nutrient to the Angiosperm partner when is not available in the medium (Harley and Smith 1983; Ashford et al. 1994).

The decrease of the orthophosphate pool in mycorrhizal plants can be due to a higher consumption of phosphate by the plants resulting from an increased metabolism due to mycorrhizal association or to a decreased orthophosphate accumulation by these plants, since they can use the polyphosphates pool provided by the fungus. This ability would confer a selective advantage to mycorrhizal plants in the case of phosphate availability fluctuation.

The results obtained for phosphate and nitrogen contents of mycorrhizal and nonmycorrrhizal plants showed that mycorrhizal plants have higher contents of both phosphate and nitrogen than nonmycorrhizal ones, either in roots, leaves or stems (Tables 1,2). Phosphate and nitrogen contents decrease with time. The increased phosphate and nitrogen content in whole mycorrhizal plants results not only from the presence of the mycorrhizal fungus in the root system, but also from their increased
Table 2 Nitrogen content $(\mu \mathrm{mol} / \mathrm{g} \mathrm{dw})$ of roots, leaves stems and total plant of nonmycorrhizal (CR, CL, CS, CT) and mycorrhizal (MR, ML, MS, MT) plants after 30, 40, 60 and 90 days of mycorrhizal synthesis. Mean values within a sampling followed by different letters are significantly different at $\mathrm{P}<0.05$

\begin{tabular}{llrrr}
\hline$\mu \mathrm{mol} / \mathrm{g} \mathrm{dw}$ & 30 days & 40 days & 60 days & 90 days \\
\hline CR & $107.9 \mathrm{a}$ & $79.1 \mathrm{a}$ & $79.8 \mathrm{a}$ & $96.0 \mathrm{a}$ \\
MR & $154.2 \mathrm{~b}$ & $141.1 \mathrm{~b}$ & $98.0 \mathrm{~b}$ & $105.8 \mathrm{~b}$ \\
CS & $140.5 \mathrm{a}$ & $92.0 \mathrm{a}$ & $106.8 \mathrm{a}$ & $92.9 \mathrm{a}$ \\
MS & $140.7 \mathrm{a}$ & $136.7 \mathrm{~b}$ & $131.5 \mathrm{~b}$ & $101.4 \mathrm{~b}$ \\
CL & $106.0 \mathrm{a}$ & $106.3 \mathrm{a}$ & $98.2 \mathrm{a}$ & $91.9 \mathrm{a}$ \\
ML & $154.4 \mathrm{~b}$ & $130.6 \mathrm{~b}$ & $119.1 \mathrm{~b}$ & $144.1 \mathrm{~b}$ \\
CT & $119.5 \mathrm{a}$ & $95.9 \mathrm{a}$ & $97.3 \mathrm{a}$ & $93.7 \mathrm{a}$ \\
MT & $140.4 \mathrm{~b}$ & $134.5 \mathrm{~b}$ & $118.2 \mathrm{~b}$ & $121.1 \mathrm{~b}$ \\
\hline
\end{tabular}

content in leaves and stems following their translocation from roots.

As already reported, micropropagated chestnut plants showed increased growth and photosynthetic rates following in vitro mycorrhization with $P$. tinctorius (Martins et al. 1996, 1997). The higher phosphate content in these plants revealed by both NMR and chemical analysis is in agreement with our previous results. This suggests a relationship between phosphate content and photosynthetic rates as also reported by other authors and for other mycorrhizal systems (Osmond 1981; Coombs 1985; Foyer and Spencer 1986; Jakobsen 1991). The stimulation of the net photosynthesis following mycorrhizal infection can however, be independent of a nutritional effect since an increase in phosphate content in nonmycorrhizal plants did not result in increased photosynthesis (Conjeaud et al. 1996). C. sativa mycorrhizal plants show increased growth rates following increased contents of $\mathrm{P}$ (Table 1) and of total N (Table 2) as reported for pine (Reid et al. 1983). These results are different from those reported by Conjeaud et al. (1996) for pine seedlings. The phosphorus content of mycorrhizal and nonmycorrhizal plants along mycorrhizal establishment is similar to that obtained from ${ }^{31} \mathrm{P}-\mathrm{NMR}$ analysis. The NMR analysis showed that the orthophosphate is the phosphate form that mainly decreases in mycorrhizal plants along the experimental time.

From the results reported we can consider that $P$. tinctorius is able to accumulate phosphate as polyphosphates as already reported for P. tinctorius (Ashford et al. 1994) and other fungi species by several authors (Chilvers et al. 1985; Martin et al. 1983, 1985; Tillard et al. 1989). Polyphosphates can already be detected in mycorrhizal roots after 3 weeks of mycorrhizal synthesis in vitro. Mycorrhizal chestnut plants can use polyphosphates as a pool for their own metabolism along the mycorrhizal establishment.

The differences in phosphate content between mycorrhizal and nonmycorrhizal plants decreased with time. The maintenance of the mycorrhizal system under in vitro conditions, without external nutrient supply, may be responsible for the decrease in the differences on phosphate contents of both mycorrhizal and nonmycorrhizal chestnut plants. 


\section{References}

Ashford AE, Ryde S, Barrow KD (1994) Demonstration of a short chain polyphosphate in Pisolithus tinctorius and the implications for phosphorus transport. New Phytol 126:239-247

Botton B (1996) Regulation of the nitrogen-assimilating enzymes in ectomycorrhizas. In: Azcon-Aguilar C, Barea JM (eds) Proceedings of the fourth European Symposium on Mycorrhizas. Mycorrhizas in integrated systems from genes to plant development, pp 294-300

Bougher NL, Grove TS, Malajczuk N (1990) Growth and phosphorus acquisition of karri (Eucalyptus diversicolor F. Muell.) seedlings inoculated with ectomycorrhizal fungi in relation to phosphorus supply. New Phytol 114:77-85

Bowen GD (1973) Mineral nutrition of mycorrhizas. In: GC Marks, TT Kozlowski (eds) Ectomycorrhizas. Academic Press, New York, pp 151-201

Bowman RA (1988) A rapid method to determine total phosphorus in soils. Soil Sci Soc Am J 52:1301-1304

Cairney JWG, Smith SE (1992) Influence of intracellular phosphorus concentration on phosphate absorption by the ectomycorrhizal basidiomycete Pisolithus tinctorius Mycol Res 96: 673-676

Chilvers GA, Lapeyrie FF, Douglass PA (1985) A contrast between Oomycetes and other and other taxa of mycelial fungi in regard to metachromatic granule formation. New Phytol 99: 203-210

Conjeaud C, Scheromm P, Mousain D (1996) Effects of phosphorus and ectomycorrhiza on maritime pine seedlings (Pinus pinaster). New Phytol 133:345-351

Coombs J (1985) Carbon metabolism. In: Coombs J, Hall DO, Long SP, Scurlock JMO (eds). Techniques in bioproductivity and photosynthesis. Pergamon Press, Oxford, pp 139-157

Cox GC, Moran KJ, Sanders F, Nockolds C, Tinker PB (1980) Translocation and transfer of nutrients in vesicular-arbuscular mycorrhizas. III. Polyphosphate granules and phosphorus translocation. New Phytol 84:649-659

Finlay RD (1992) Uptake and translocation of nutrients by ectomycorrhizal fungal mycelia. In: Read DJ, Lewis DH, Fitter AH, Alexander IJ (eds) Mycorrhizas in ecosystems. CAB International, Cambridge, UK, pp 91-97

Finlay RD, Brun A, Chalot M, Söderstrom B (1996) Interactions in the carbon and nitrogen metabolism of ectomycorrhizal associations. In: Azcon-Aguilar C, Barea JM (eds) Proceedings of the fourth European symposium on mycorrhizas. Mycorrhizas in integrated systems from genes to plant development, pp 279-283

Forster JC (1995) Soil nitrogen. In: Alef K, Nannipieri P (eds) Methods in applied soil microbiology and biochemistry. Academic Press, London, UK, pp 79-81

Foyer C, Spencer C (1986) The relationship between phosphate status and photosynthesis in leaves. Effects on intracellular orthophosphate distribution, photosynthesis and assimilate partitioning. Planta 167:369-375

Grellier B, Strullu DG, Martin F, Renaudin S (1989) Synthesis in vitro, microanalysis and ${ }^{31} \mathrm{P}-\mathrm{NMR}$ study of metachromatic granules in birch mycorrhizas. New Phytol 112:49-54

Harley JL, Smith SE (1983) Mycorrhizal symbiosis. Academic Press, Toronto

Jakobsen I (1991) Carbon metabolism in mycorrhiza. In: Norris JR, Norris DJ, Varma AK (eds) Methods in microbiology, vol 23. Academic Press, London, UK, pp 149-180
John MK (1970) Colorimetric determination of phosphorus in soil and plant materials with ascorbic acid. Soil Sci 109:214 220

Jones MD, Durall DM, Tinker PB (1990) Phosphorus relationships and production of extramatrical hyphae by two types of willow ectomycorrhizas at different soil phosphorus levels. New Phytol 115:259-267

Jones MD, Durall DM, Tinker PB (1991) Fluxes of carbon and phosphorus between symbionts in willow ectomycorrhizas and their changes with time. New Phytol 119:99-106

Keeney DR, Nelson DW (1982) Nitrogen inorganic forms. In: Page Al, Miller DR, Keeney DR (eds) Methods of soil analysis, part 2. Chemical and microbiological methods. Agronomy 9 (2), ASA, SSSA, Madison, Wis., pp 643-698

Longstreth DJ, Nobel, PS (1980) Nutrient influences on leaf photosynthesis. Effects of nitrogen, phosphorus and potassium for Gossypium hirsutum L. Plant Physiol 65:541-543

Loughman BC, Ratcliff RG (1984) Nuclear magnetic resonance and the study of plants. Adv Plant Nutr 1:241-283

MacFall JS, Slack SA, Wehrli S (1992) Phosphorus distribution in red pine roots and the ectomycorrhizal fungus Hebeloma arenosa. Plant Physiol 100:713-717

Martin F, Canet D, Rolin D, Marchal JP and Larher F (1983) Phosphorus-31 nuclear magnetic resonance study of polyphosphate metabolism in intact ectomycorrhizal fungi. Plant Soil 71:469-476

Martin F, Marchal JP, Timinska A, Canet D (1985) The metabolism and physical state of polyphosphate in ectomycorrhizal fungi. A ${ }^{31} \mathrm{P}$ nuclear magnetic resonance study. New Phytol 101:275-290

Martins A, Barroso J, Pais MS (1996) Effect of ectomycorrhizal fungi on survival and growth of micropropagated plants and seedlings of Castanea sativa Mill. Mycorrhiza 6:265-270

Martins A, Casimiro A, Pais MS (1997) Influence of mycorrhization on physiological parameters of Castanea sativa Mill. micropropagated plants. Mycorrhiza 7:161-165

Marx DH (1969) The influence of ectotrophic mycorrhizal fungi on the resistance of pine roots to pathogenic infections. I. Antagonism of mycorrhizal fungi to root pathogenic fungi and soil bacteria. Phytopathology 59:153-163

Osman AM, Goodman PJ, Cooper JP (1977) The effects of nitrogen, phosphorus and potassium on rates of growth and photosynthesis of wheat. Photosynthetica 11:66-75

Osmond CB (1981) Photorespiration and photoinhibition. Some implications for the energetic of photosynthesis. Biochim Biophys Acta 639:77-98

Reid CPP, Kidd FA, Ekwebelam SA (1983) Nitrogen nutrition, photosynthesis and carbon allocation in ectomycorrhizal pine. Plant Soil 71:415-431

Smith SE, Read DJ (1997) Mycorrhizal symbiosis. Academic Press, Cambridge, UK

Son CL, Smith SE (1988) Mycorrhizal growth responses: interactions between photon irradiance and phosphorus nutrition. New Phytol 108:305-314

Swada S, Igarashi T, Miyachi S (1982) Effects of nutritional levels of phosphate on photosynthesis and growth studied with single, rooted leaf of dwarf bean. Plant Cell Physiol 23:27-33

Tillard P, Bousquet N, Mousain D, Martin F, Salsac L (1989) Polyphosphate activities in the soluble fraction of mycelial homogenates in Pisolithus tinctorius. Agric Ecosys Environ 28:525-528 